\title{
Effectiveness of Direct Seeding for Forest Restoration on Severely Degraded Land in Lampang Province, Thailand
}

\author{
Farzana Hossain1, Stephen Elliott ${ }^{2}$, Sutthathorn Chairuangsri1,2* \\ ${ }^{1}$ Faculty of Science, Chiang Mai University, Chiang Mai, Thailand \\ ${ }^{2}$ The Forest Restoration Research Unit, Department of Biology, Science Faculty, Chiang Mai University, \\ Chiang Mai, Thailand \\ Email: s.suwann@gmail.com
}

Received 19 August 2014; revised 21 September 2014; accepted 30 September 2014

Copyright (C) 2014 by authors and Scientific Research Publishing Inc.

This work is licensed under the Creative Commons Attribution International License (CC BY). http://creativecommons.org/licenses/by/4.0/

(c) (i) Open Access

\section{Abstract}

This study tested the effectiveness of direct seeding to establish framework tree species, for restoring forest ecosystems at an opencast lignite mine in Lampang Province, Thailand. A randomized complete block design (RCBD) experiment tested five tree species (Afzelia xylocarpa (Kurz) Craib, Eugenia cumini (L.) Druce, Ficus racemosa Roxb., Gmelina arborea Roxb. and Schleichera oleosa (Lour.) Oken) with 5 substrate amelioration treatments and 3 replicates. Germination percent was the highest for Afzelia xylocarpa (88.1\%) and lowest for Ficus racemosa (5.9\%). The substrate amelioration treatments had no significant effects on both seed germination and seedling establishment for all species tested. Schleichera oleosa had the highest seedling establishment percent $(45 \%)$ followed by Afzelia xylocarpa (40\%). A suitability scoring system indicated that these two species were the most suitable for direct seeding to complement other techniques of mine site rehabilitation in northern Thailand, where establishment of indigenous forest tree species is required for biodiversity recovery.

\section{Keywords}

Direct Seeding, Forest Restoration, Lignite Mine, Soil Treatments, Suitability Score

\section{Introduction}

Worldwide, around 13 million ha of forests are destroyed or degraded each year, according to the Food and Agriculture Organization of the UN (FAO, 2010). The main cause is conversion of forestland to agriculture

${ }^{*}$ Corresponding author.

How to cite this paper: Hossain, F., Elliott, S., \& Chairuangsri, S. (2014). Effectiveness of Direct Seeding for Forest Restoration on Severely Degraded Land in Lampang Province, Thailand. Open Journal of Forestry, 4, 512-519. 
(FAO, 2007; FAO, 2010), but infrastructure developments, also play a major role. Thailand's Northern provinces were once densely forested, but over the past 100 years, natural forest cover has significantly declined (Walker, 2002). Despite a ban on commercial logging since 1989, eight kinds of infrastructure developments have wiped out over 480,000 hectare of Thailand's forests ( $10 \%$ of total losses), over the past four decades, including 77128.96 ha destroyed by mining (www.bangkokpost.com/lifestyle/family/374915/clearing-the-way).

Mining of lignite is having a significant impact on the forests of northern Thailand, where large open cast mines, in mostly forested areas, produce around $21 \mathrm{Mt} / \mathrm{y}$, almost exclusively for power generation (Kessels, 2010). With an estimated $1400 \mathrm{Mt}$ of recoverable reserves remaining, the problem of rehabilitating such mines is likely to grow in the future. Mining has huge adverse effects on the surrounding environment, including removal of topsoil and overburden, as well as changes to topography, streams and vegetation. Although Thai Government laws require restoration of natural forest to mine sites (Sivavong and Limkitisupasin, 2005), mining companies are struggling to come up with effective methods to re-establish natural forest ecosystems on such harsh, degraded sites.

Research on forest rehabilitation has often focused on the use of tree plantations to accelerate secondary succession in altered areas (Parrotta, 1992; Lugo, 1997), whilst the most ambitious goal of restoration is the re-establishment of high levels of biomass, structural complexity, biodiversity and ecological functioning, similar to that of the indigenous climax forest ecosystem (Elliott et al., 2013; Schmidt-Vogt, 2001; Nepstad et al., 1996). In recent years, new forms of forest restoration may offer alternative ways of dealing with degraded tropical forest landscapes. Two broad approaches have been tested; one is to use a small number of indigenous tree species to create canopy cover, whilst additional native species reach the site by natural seed dispersal from nearby intact forest.

The framework species method of forest restoration firstly developed in Queensland, Australia (Goosem and Tucker 1995; Lamb et al. 1997; Tucker 2000; Tucker and Murphy 1997). It has been successfully adapted to restore several Thailand's forest types on non-mine sites (Elliott et al., 2013). It only works where mature forest and seed-dispersing animals still exist nearby. Another approach uses a much greater number of species, representative of more mature succession stages, without relying so much on natural succession to complete biodiversity recovery (Lamb et al., 2005). This is the maximum diversity approach (Goosem and Tucker, 1995). It requires sufficient ecological knowledge to collect seeds and germinate large numbers of seedlings from a wide variety of species (FORRU, 2006) and the key limitation is high cost (Erskine, 2002).

Tree planting is costly and requires high labor inputs. Direct seeding can significantly reduce restoration costs because labor and time for raising seedlings in nurseries are not required (Woods and Elliott, 2004). However, the technique is constrained by the need for adequate soil moisture, to create optimum conditions for germination and early seedling growth (Moles and Westoby, 2006; Shankar, 2006). Therefore, soil amelioration treatments could greatly increase the efficiency of the technique, particularly on more degraded sites, such as mines, although little field research has been done on the effectiveness of soil conditioning materials. Consequently, this project tested the effectiveness of direct seeding of framework species in a lignite mine site, and determined whether soil conditioners could substantially improve success rate.

\section{Methodology}

\subsection{Study Site}

This study was carried out at the lignite mine of Siam Cement Group in Mae Than district, Lampang Province $\left(17^{\circ} 57^{\prime} 16^{\prime \prime} \mathrm{N}, 99^{\circ} 26^{\prime} 05^{\prime \prime} \mathrm{E}\right.$; elevation $\left.400 \mathrm{~m}\right)$, Thailand. The mean annual temperature at the site is $27.3^{\circ} \mathrm{C}$, with mean annual precipitation of $1326 \mathrm{~mm}$, most of which falls between May to October. The original vegetation of the area was forest ecosystems typical of lowland northern Thailand: deciduous, dipterocarp-oak forest along ridges and in driers sites, with seasonal, hardwood forest mixed with bamboo in along the gullies and moister sites (Maxwell and Elliott, 2001). At the beginning of the study, there was no vegetation in the study area.

\subsection{Soil Properties}

Soil tests showed that the study site soil was moderately alkaline ( $\mathrm{pH} 7.94)$ with very low organic matter content $(0.193 \%)$ and nitrogen levels, but relatively high phosphorus and medium potassium levels compared with the normal soil properties range (Jensen, T. L., 2010; see Table 1). 
Table 1. Chemical properties of the soil.

\begin{tabular}{|c|c|c|c|c|c|c|}
\hline Chemical properties & $\mathrm{pH}^{\mathrm{d}}$ & $\mathrm{OM}^{\mathrm{d}}$ & Total N (mg/kg) & $\begin{array}{c}\text { Organic } \\
{\text { carbon }(\%)^{\mathrm{d}}}^{\text {a }}\end{array}$ & $\begin{array}{l}\text { Available P } \\
(\mathrm{mg} / \mathrm{kg})^{\mathrm{c}}\end{array}$ & $\begin{array}{l}\text { Exchangeable K } \\
\text { (mg/kg) }^{\mathrm{d}}\end{array}$ \\
\hline Average $^{a}$ & 7.94 & 0.193 & 0.06 & 0.11 & 48.59 & 110.05 \\
\hline
\end{tabular}

${ }^{\mathrm{a} A v e r a g e ~ v a l u e ~ f o r ~ t h e ~ c h e m i c a l ~ p r o p e r t i e s ~}(\mathrm{n}=6)$, ${ }^{\mathrm{b}}$ Total-N (Bremner \& Mulvaney, 1982). ${ }^{\mathrm{C}}$ Available-P (Olsen \& Sommers, 1982), ${ }^{\mathrm{d} O t h e r s ~ c h e m i c a l ~}$ properties-Siwasil, 1984.

\subsection{Seed Storage}

Five indigenous forest tree species were selected: Afzelia xylocarpa (Kurz) Craib, Eugenia cumini (L.) Druce, Ficus racemosa Roxb., Gmelina arborea Roxb., and Schleichera oleosa (Lour.) (Table 2). All had been tested by Chiang Mai University's Forest Restoration Research Unit (FORRU-CMU) in previous nursery experiments and restoration field trials on non-mine sites and all fruited in time for seed collection at the start of the study period (May-June); coinciding with the optimum time for direct seeding (FORRU, 2008). Seeds were collected from CMU campus and nearby forest. Except for Eugenia cumini all fruits were collected from the ground, when seeds were properly developed and matured. Fruits were stored in open plastic bags, out of direct sunlight, for one to two days, until seeds were extracted. Except for Afzelia xylocarpa (which has a hard seed coat) the fruit pulp was removed and the seeds rinsed with water. Seeds were then spread out on paper and air dried in shade overnight, after which the seeds were stored (approximately one and half months) in airtight jars at room temperature except Eugenia cumini, which was stored in a refrigerator. Before the trial, the seeds were prepared with pre-sowing treatment following the FORRU methodology (FORRU, 2006).

\subsection{Materials}

Biosolids were obtained from the Pepsi Cola-Lays Company's waste water plant, Lamphun, Thailand. The waste was generated from potato chip production. It had a $\mathrm{pH}$ of 7.72 and contained $19.75 \mathrm{~g}$ organic matter per $100 \mathrm{gm}$ (dry mass), $1.57 \mathrm{~g} / \mathrm{kg}$ total-nitrogen, $68.72 \mathrm{mg} / \mathrm{kg}$ phosphorus and $777.7 \mathrm{mg} / \mathrm{kg}$ potassium. Compost used in this study was made from urban organic wastes and cow feces in the ratio 3:1. The fertilizer used in this experiment was $\mathrm{N}: \mathrm{P}: \mathrm{K}, 1: 2: 1$.

\subsection{Direct Seeding Experiment Design}

The field trial was a randomized complete block design (RCBD) with 5 substrate amelioration treatments and 3 replicates. The treatments were: 1 ) biosolids (1 kg) +fertilizer (50 g); 2) biosolids (1 kg) - fertilizer; 3) compost (1 kg) + fertilizer (50 g); 4) compost (1 kg) - fertilizer and 5) control (no substrate amelioration treatment). Each replicate sub-plot consisted of 36 seed sowing points, each marked by a bamboo pole (color coded by treatment), about $1.2 \mathrm{~m}$ apart, laid out in a square grid pattern $6 \times 6$ points over $7.2 \times 7.2 \mathrm{~m}^{2}$. At each sowing point, one seed of each of the five species was sown into PVC tubes $(5.5 \mathrm{~cm}$ in diameter) about $40 \mathrm{~cm}$ apart (color coded to match the species). Seed germination was monitored every week for 3 months. Germination data were collected every one week, to calculate per cent germination and length of dormancy. For each seedling germinated in the field; height, RCD (root collar diameter) and health score $(0=$ dead to $3=$ good health) were recorded for 5 months (FORRU, 2008).

\subsection{Data Analysis}

Data were analyzed by Microsoft Excel 2007 Data Analysis Tool pack. The median length of dormancy (MLD) and percent germination were calculated at the end of the germination trial. A two way ANOVA without replication was performed to detect any significant differences in germination and establishment percentages among species and treatments in the experiment. Student's t-test (paired two samples for means) was performed when ANOVA results showed any significant differences on Percent germination, percent establishment in experiment conditions.

A performance score was calculated based on establishment, combined with RCD to determine which species were most suitable for direct seeding on mine sites. First, species with survival percentages less than $10 \%$ by the 
Table 2. Seed characteristics of the studied species.

\begin{tabular}{cccccc}
\hline Species & $\begin{array}{c}\text { Afzelia xylocarpa } \\
\text { (Kurz) craib }\end{array}$ & $\begin{array}{c}\text { Eugenia cumini L. } \\
\text { Druce }\end{array}$ & Ficus racemosa L. & Gmelina arborea Roxb. & $\begin{array}{c}\text { Schleichera oleosa } \\
\text { (Lour.) oken }\end{array}$ \\
\hline Family & Leguminosae & Myrtaceae & Moraceae & Verbenaceae & Sapiandaceae \\
Seed sizea & Large & Small & Small & Medium & Medium \\
Seed coatb & Thick & Thin & Thin & Thick & Thick \\
Seed shapec & Ovoid & Round & Round & Ovoid & Ovoid \\
Orthodox/Recalcitrant & Orthodox & Recalcitrant & Orthodox & Intermediate & Orthodox/ \\
& & Intermediate \\
Pre-sowing treatment & Scarification & Soaked in water & Nothing & Soaked in water and & Soaked in water \\
and dried in shade & sundried & and sund \\
\hline
\end{tabular}

${ }^{\mathrm{a}}$ Seed size category based on seed weight: S small ( $<0.01-0.099$ g); I intermediate (0.1 - 4.99 g); L Large ( $>5.0$ g) (seed size category determined from mean of a random sample of no less than 20 seeds per species) (Doust et al. 2006). ${ }^{\mathrm{b}}$ Seed coat thickness: Thin $(<0.01-0.099 \mathrm{~mm})$; moderate $(0.1$ - $0.49 \mathrm{~mm})$; Thick $(>0.5 \mathrm{~mm}$ ) (FORRU, Database). Seed shape: R round (variance $<0.06)$; O = Oval (variance $=0.06-0.09)$; F flat $($ variance $>0.09)$.

middle of 2nd rainy season (expressed as a percentage of seed sown) were rejected. Then for all those species which exceeded this threshold, the score was calculated using the formula:

$$
\text { Suitability Score }=\text { establishment } \times R C D
$$

\section{Results}

\subsection{Species Comparisons}

Germination percentages, averaged across all treatments, differed significantly among species $(p<0.05)$. Highest germination was achieved by A. xylocarpa $88 \%$ and lowest by F. racemosa $5.9 \%$. T-tests revealed that percent germination of Afzelia xylocarpa and Schleichera oleosa was significantly higher than that of other species, across all treatments. Three species exhibited rapid germination (i.e. short MLD) (A. xylocarpa, S. oleosa and G. arborea $)(p<0.05)$.

\subsection{Treatment Effect}

Germination by treatment, averaged across species, was highest with biosolids + fertilizer (46\%) and lowest with compost + fertilizer (39\%) (Table 3). Overall, average seedling establishment was $20 \%$, across all treatments; highest with biosolids + fertilizer and lowest with compost + fertilizer (Table 3). Remarkably, percent germination and total seedling establishment with the control were very close to those achieved with the biosolids + fertilizer treatment.

\subsection{Suitability Score}

The overall performance of Afzelia xylocarpa and Schleichera oleosa was outstanding, within treatments. The rank suitability score of Afzelia xylocarpa and Schleichera oleosa was more than $40 \%$ (See 2.6). Highest score was achieved by Afzelia xylocarpa in biosolids + fertilizer (and was assigned a value of 100\%) (Table 4). Schleichera oleosa achieved the second highest score, where the rank score was highest for the control 84.5\%. The other three species Eugenia cumini, Gmelina arborea and Ficus racemosa were not considered suitable for direct seeding , because their percent establishment was less than 10\% (Table 4). Species with high germination rates also had high seedling establishment rates. Averaging across all treatments, Afzelia xylocarpa and Schleichera oleosa had significantly higher establishment rates (above 40\%), compared with the other 3 species, in almost every treatment $(p<0.05)$ (Figure $1(b))$.

\section{Discussion}

Species, suitable for direct seeding, must have not only high germination percent, but also rapid germination. The latter minimizes the time, during which they are vulnerable to seed predation and maximizes the establishment period (particularly root growth), before onset of the dry season (Lamb, 2011). Rapid seedling growth is 
Table 3. Treatment means across species of percent germination, MLD and establishment rates averaged across all 5 species.

\begin{tabular}{cccccc}
\hline & Biosolids + fertilizer & Biosolids & Compost + fertilizer & Compost & Control \\
\hline No. of seed sown in five species & 540 & 540 & 540 & 540 & 540 \\
No. of germinated seed & 249 & 229 & 210 & 237 & 238 \\
Percent germination & $46.1(14.44)^{\mathrm{a}}$ & $42.4(15.44)^{\mathrm{a}}$ & $38.9(13.77)^{\mathrm{a}}$ & $43.9(14.77)^{\mathrm{a}}$ & $44.1(18.04)^{\mathrm{a}}$ \\
MLD (in Days) & $40(7.80)^{\mathrm{a}}$ & $30(6.69)^{\mathrm{a}}$ & $29(2.80)^{\mathrm{a}}$ & $44(7.68)^{\mathrm{a}}$ & $32(4.05)^{\mathrm{a}}$ \\
Percent seedling establishment & $22.8(8.92)^{\mathrm{a}}$ & $20.0(9.96)^{\mathrm{a}}$ & $18.0(7.78)^{\mathrm{a}}$ & $20.0(8.62)^{\mathrm{a}}$ & $21.5(10.84)^{\mathrm{a}}$ \\
\hline
\end{tabular}

*Note: Standard errors are in brackets (SE).

Table 4. Suitability score of two successful species in the direct seeding experiment.

\begin{tabular}{|c|c|c|c|c|c|}
\hline Species & Treatments & Establishment & $\begin{array}{c}\text { Root-collar } \\
\text { diameter (mm) }\end{array}$ & Raw suitability score & $\begin{array}{c}\text { Rank suitability } \\
\text { score }(0 \%-100 \%)\end{array}$ \\
\hline Afzelia xylocarpa & Biosolids + fertilizer & 47.2 & 12.0 & 569 & 100 \\
\hline Schleichera oleosa & Control & 49.1 & 9.8 & 480.8 & 84.5 \\
\hline Schleichera oleosa & Compost & 41.7 & 10.1 & 420.1 & 73.8 \\
\hline Schleichera oleosa & Biosolids + fertilizer & 41.7 & 7.8 & 326.6 & 57.4 \\
\hline Afzelia xylocarpa & Biosolids & 49.07 & 6.48 & 317.9 & 55.87 \\
\hline Schleichera oleosa & Biosolids & 38.09 & 8.0 & 312.1 & 54.8 \\
\hline Afzelia xylocarpa & Control & 46.3 & 6.5 & 300.9 & 52.9 \\
\hline Afzelia xylocarpa & Compost + Fertilizer & 43.5 & 6.1 & 266 & 46.7 \\
\hline Schleichera oleosa & Compost + fertilizer & 28.7 & 9.2 & 262.8 & 46.2 \\
\hline Afzelia xylocarpa & Compost & 39.8 & 6.4 & 256.7 & 45.1 \\
\hline
\end{tabular}

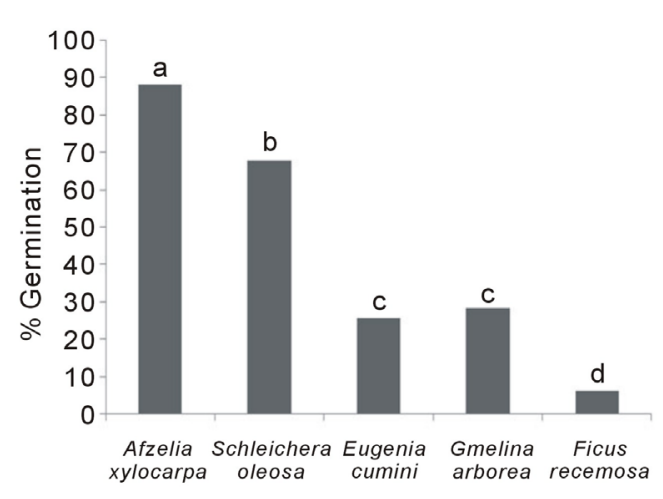

(a)

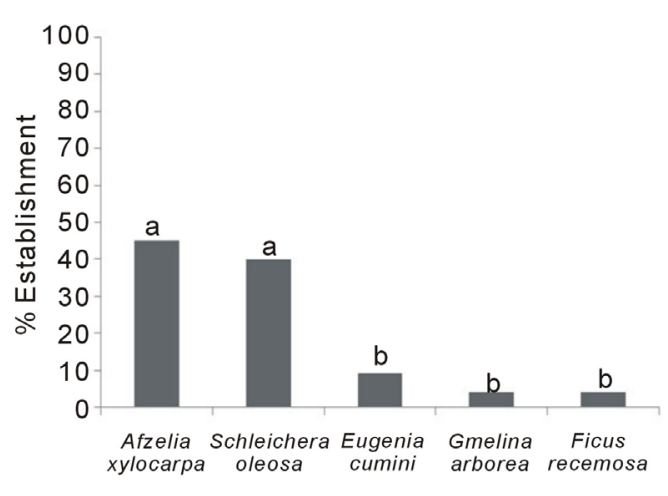

(b)

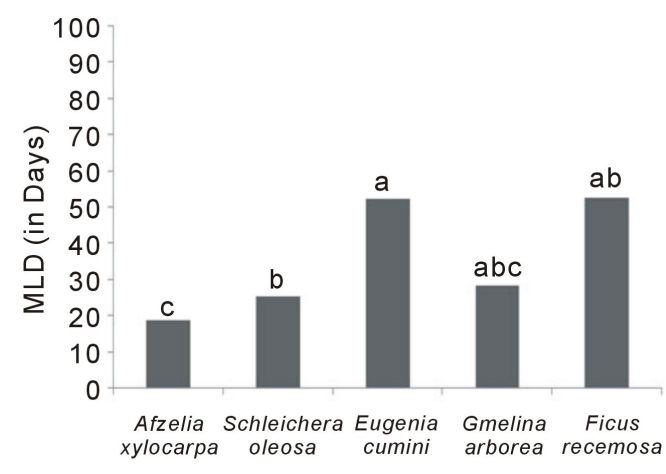

(c)

Figure 1. Species means across treatments of (a) Percent Germination, (b) Percent Establishment and (c) Median Length of Dormancy $(p<0.05)$. 
also needed for successful direct seeding, in order for tree seedlings to out-compete surrounding vegetation (Engel and Parrotta, 2001; Doust et al., 2008). Therefore, both parameters were combined to calculate the suitability score.

Seed characteristics may explain the differences in species' responses in the trial. A. xylocarpa and S. oleosa both achieved an acceptable level (i.e. percent germination and establishment were significantly higher and MLD'S were significantly shorter, compared with other species). Both species have medium to large seed size with thick seed coats, in agreement with the suitable seed characteristics for direct seeding identified by Tunjai and Elliott (2011). Large seeds have greater tolerance of stresses, since higher resources can be allocated to tolerate particular stresses, such drought or shade (Coomes \& Grubb, 2003; Helene C. Muller-Landau, 2010), whereas small-seeded species cannot tolerate stresses, because food resources within the seed are limited.

However, thick seed coats can delay germination (Tunjai, 2005), so pre-sowing treatments are often necessary to shorten dormancy, resulting from a hard seed coat. In this experiment, a pre-sowing treatment was used for the hard-coated seed species. This accounts for the shortened dormancy recorded for the hard-coated species.

The lack of treatment effects may be due to the application of insufficient amounts of the substrate amelioration substances (Table 3) or their being washed away by heavy rains. There it is suggested that site reparation should be completed before the start of the rainy season, with seeding occurring during the 2nd or 3rd week of the rainy season.

The success of A. xylocarpa might be attributable to the fact that it is a leguminous species, notable for being able to fix nitrogen (Cervantes, Carabias and Vazquez-Yanes, (1996); Garg, (1999); Siddique et al., (2008) and thus survive and grow well on degraded, nutrient poor sites (Engel and Parrotta, 2001). Furthermore, high germination percent $A$. xylocarpa was achieved by scarification to overcome seed coat dormancy (Tunjai, 2005).

The final germination percent and establishment of $S$. oleosa were also high enough to allow this species to be considered suitable for direct seeding (Figure 1). E. cumini, G. arborea and F. racemosa did not meet the acceptable standard for direct seeding, as they showed low percent of germination, as well as long MLD (Figure 1). E. cumini may have had low germination due to storing the seeds too long after collection. They were sown in the field after 30 days storage. FORRU (unpublished data) recorded a germination percent for this species of $96 \%$, with exposure to sunlight (the same pre-sowing treatment as used in this experiment). So it is likely that seeds lost viability during storage and that this species is recalcitrant G. arborea should be considered. Although germination and establishment were low, MLD was short and sapling growths rates on mine sites are known to be very high.

Lastly, F. racemosa was unacceptable for direct seeding, because of low percent germination and long dormancy Figure 1(a) \& Figure 1(c). Fig seeds are tiny. They do not contain sufficient food resources to support early seedling growth, which probably makes them unsuitable for direct seeding (Kuaraksa \& Elliott, 2013; Hua, 1997).

The suitability score was calculated from percent establishment and growth performance by the middle of the 2nd rainy season after sowing (Table 4). Species with suitability scores exceeding 40 would be excellent candidate species for direct seeding; S. oleosa and, A. xylocarpa were suitable for direct seeding as they got suitability scores above $40 \%$.

However, further study is needed to ensure wider acceptability of this technique. Compact substrates are vulnerable to accumulation of surface water, which was a problem in this study. Further experiments are needed to determine which species may more resistant to water logging. Top soil replacement also needs further investigation, to improve aeration and drainage and provide developing seedlings with more nutrients. This may improve the success rate of direct seeding of more species. Top soil replacement worked very well for conventional seedling planting trials at a nearby mine (Lime stone mine, FORRU (unpublished data)). Further experiments should be conducted on managing the soil ph, since the soil report indicated an acidic soil. Further experiments should also be conducted to test the effects of microbial treatments (Shetty et al., 1994).

\section{Conclusion}

In conclusion, direct seeding could make a significant contribution towards mine restoring forest to open cast mines, although the number of species that respond well to the method is limited and further work is clearly needed to develop suitable soil treatments to improve the success rate. This paper showed that A. xylocarpa and S. oleosa have already been used successfully for direct seeding on mine sites in northern Thailand to complement conventional tree planting of other species. Top soil replacement is recommended for further investigation 
to develop the techniques for other species.

\section{Acknowledgements}

We thank the staff of the Forest Restoration Research Unit, Chiang Mai University for their assistance, as well as SCG staff at the Lampang mine for logistical support on-site. We are also very grateful for institutional support from Environmental Science Program in Chiang Mai University. Last but not the least; I would like to give special thanks to Elephant Nature Park for their cordiality to sponsor the study coast for my Master's degree in Chiang Mai University.

\section{References}

Cervantes, V., Carabias, J., \& Vazquez-Yanes, C. (1996). Seed Germination of Woody Legumes from Deciduous Tropical Forest of Southern Mexico. Forest Ecology and Management, 82, 171-184. http://dx.doi.org/10.1016/0378-1127(95)03671-7

Coomes, D. A., \& Grubb, P. J. (2003). Colonization, Tolerance, Competition and Seed-Size Variation within Functional Groups. Trends in Ecology \& Evolution, 18, 283-291. http://dx.doi.org/10.1016/S0169-5347(03)00072-7

Doust, S. J., Erskine, P. D., \& Lamb, D. (2006). Direct Seeding to Restore Rainforest Species: Micro Site Effects on the Early Establishment and Growth of Rainforest Tree Seedlings on Degraded Land in the Wet Tropics of Australia. Forest Ecology and Management, 234, 333-343. http://dx.doi.org/10.1016/j.foreco.2006.07.014

Doust, S. J., Erskine, P. D., \& Lamb, D. (2008). Restoring Rainforest Species by Direct Seeding: Tree Seedling Establishment and Growth Performance on Degraded Land in the Wet Tropics of Australia. Forest Ecology and Management, 256, 1178-1188. http://dx.doi.org/10.1016/j.foreco.2008.06.019

Elliott, S., Blakesley, D., \& Hardwick, K. (2013). Restoring Tropical Forests: A Practical Guide. Royal Botanical Garden, Kew: Kew Publishing.

Engel, V. L., \& Parrotta, J. (2001). An Evaluation of Direct Seeding for Reforestation of Degraded Lands in Central Sao Paulo State, Brazil. Forest Ecology and Management, 152, 169-181. http://dx.doi.org/10.1016/S0378-1127(00)00600-9

FAO (2007). State of the World's Forests. Rome: Food and Agriculture Organization of the United Nations.

FAO (2010). State of the World's Forests. Rome: Food and Agriculture Organization of the United Nations.

FORRU (2008) Research for Restoring Tropical Forest Ecosystems: A Practical Guide. Chiang Mai: Chiang Mai University.

Garg, V. K. (1999). Leguminous Trees for the Rehabilitation of Sodic Wasteland in Northern India. Restoration Ecology, 7 , 281-287. http://dx.doi.org/10.1046/j.1526-100X.1999.72021.x

Goosem, S., \& Tucker, N. I. J. (1995). Repairing the Rainforest. Cairns: Wet Tropics Management Authority. http://www.wettropics.gov.au/media/med_landholders.html

Hau, C. H. (1997). Tree Seed Predation on Degraded Hillsides in Hong Kong. Forest Ecology and Management, 99, $215-221$. http://dx.doi.org/10.1016/S0378-1127(97)00207-7

Kessels, J. (2010). Prospects for Coal and Clean Coal Technologies in Thailand. Bangkok: IEA Clean Coal Centre.

Kuaraksa, C., \& Elliott, S. (2013). The Use of Asian Ficus Species for Restoring Tropical Forest Ecosystems. Restoration Ecology, 21, 86-95. http://dx.doi.org/10.1111/j.1526-100X.2011.00853.x

Lamb, D., Parrotta, J., Keenan, R., \& Tucker, N. (1997). Rejoining Habitat Remnants: Restoring Degraded Rainforest Lands. Chicago, IL: University of Chicago Press.

Lamb, D., Erskine, P. D., \& Parrotta, J. A. (2005). Restoration of Degraded Tropical Forest Landscapes. Science, 310, 1628-1632. http://dx.doi.org/10.1126/science.1111773

Lamb, D. (2011). Regreening the Bare Hills: Tropical Forest Restoration in the Asia-Pacific Region. New York: Springer. http://dx.doi.org/10.1007/978-90-481-9870-2

Lugo, A. E. (1997). The Apparent Paradox of Reestablishing Species Richness on Degraded Lands with Tree Monocultures. Forest Ecology and Management, 99, 9-19. http://dx.doi.org/10.1016/S0378-1127(97)00191-6

Maxwell, J. F., \& Elliott, S. (2001). Vegetation and Vascular Flora of Doi Sutep-Pui National Park, Chiang Mai Province, Thailand. Thai Studies in Biodiversity 5, Biodiversity Research and Training Programme, Bangkok.

Maxwell, J. F. (2012). Siam Cement Group Lignite Mine Vegetation Survey. Chiang Mai: CMU Herbarium, Biology Department, Chiang Mai University.

Moles, A. T., \& Westoby, M. (2006). Seed Size and Plant Strategy across the Whole Life Cycle. Oikos, 113, 91-105. http://dx.doi.org/10.1111/j.0030-1299.2006.14194.x 
Muller-Landau, H. C. (2010). The Tolerance-Fecundity Trade-Off and the Maintenance of Diversity in Seed Size. Proceedings of the National Academy of Sciences of the United States of America, 107, 4242-4247. http://dx.doi.org/10.1073/pnas.0911637107

Nepstad, D. C., Uhl, C., Pereira, C. A., \& da Silva, J. M. C. (1996). A Comparative Study of Tree Establishment in Abandoned Pasture and Mature Forest of Eastern Amazonia. Oikos, 76, 25-39. http://dx.doi.org/10.2307/3545745

Parrotta, J. A. (1992). The Role of Plantation Forests in Rehabilitating Degraded Tropical Ecosystems. Agriculture, Ecosystems \& Environment, 41, 115-133. http://dx.doi.org/10.1016/0167-8809(92)90105-K

Schmidt-Vogt, D. (2001). Secondary Forests in Swidden Agriculture in the Highlands of Thailand. Journals of Tropical Forest Science, 13, 748-767.

Shankar, U. (2006). Seed Size as a Predictor of Germination Success and Early Seedling Growth in "Hollong” (Dipterocarpus macrocarpus Vesque). New Forests, 31, 305-320. http://dx.doi.org/10.1007/s11056-005-8198-6

Sivavong, V., \& Limkitisupasin, N. (2005). Thailand Coal Demand for Power Generation in 2004-2015. Thailand: Electricity Generating Authority of Thailand (EGAT).

Shetty, K. G., Hetrick, B. A. D., Figge, D. A. H., \& Schwab, A. P. (1994). Effects of Mycorrhizae and Other Soil Microbes on Revegetation of Heavy Metal Contaminated Mine Spoil. Environmental Pollution, 86, 181-188. http://dx.doi.org/10.1016/0269-7491(94)90189-9

Siddique, I., Engel, V. L., Parrotta, J. A., Lamb, D., Nardoto, G. B., Ometto, J. P. H. B., Martinelli, L. A. and Schmidt, S. (2008). Dominance of Legume Trees Alters Nutrient Relations in Mixed Species Forest Restoration Plantings within Seven Years. Biogeochemistry, 88, 89-101. http://dx.doi.org/10.1007/s10533-008-9196-5

Tucker, N. I. (2000). Wildlife Colonisation on Restored Tropical Lands: What Can It Do, How Can We Hasten It and What Can We Expect. Proceedings Forest Restoration for Wildlife Conservation, Chiang Mai, 30th January-4th February 2000, 279-295.

Tucker, N. I., \& Murphy, T. M. (1997). The Effects of Ecological Rehabilitation on Vegetation Recruitment: Some Observations from the Wet Tropics of North Queensland. Forest Ecology and Management, 99, 133-152. http://dx.doi.org/10.1016/S0378-1127(97)00200-4

Tunjai, P., \& Elliott, S. (2011). Effects of Seed Traits on the Success of Direct Seeding for Restoring Southern Thailand's Lowland Evergreen Forest Ecosystem. New Forests, 43, 319-333. http://dx.doi.org/10.1007/s11056-011-9283-7

Walker, A. (2002). Forests and Water in Northern Thailand. CMU. Journal, 1, 215-244.

Woods, K., \& Elliott, S. (2004). Direct Seeding for Forest Restoration on Abandoned Agricultural Land in Northern Thailand. Journal of Tropical Forest Science, 16, 248-259.

http://www.bangkokpost.com/lifestyle/family/374915/clearing-the-way 
Scientific Research Publishing (SCIRP) is one of the largest Open Access journal publishers. It is currently publishing more than 200 open access, online, peer-reviewed journals covering a wide range of academic disciplines. SCIRP serves the worldwide academic communities and contributes to the progress and application of science with its publication.

Other selected journals from SCIRP are listed as below. Submit your manuscript to us via either submit@scirp.org or Online Submission Portal.
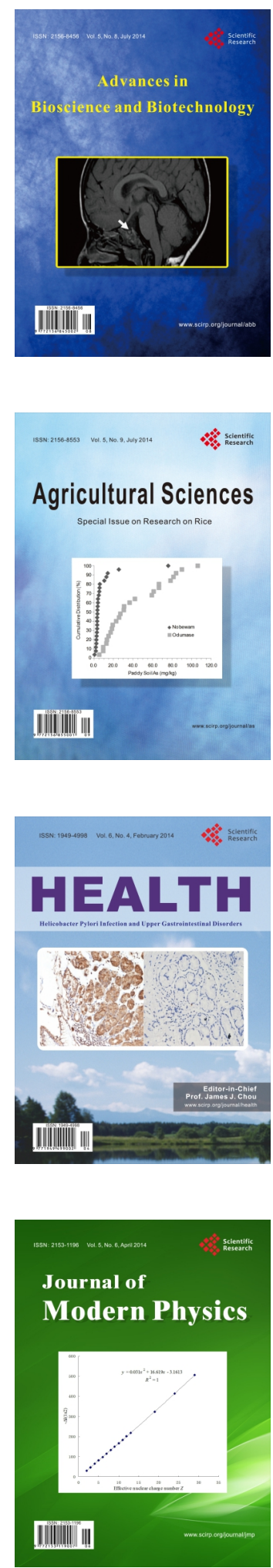
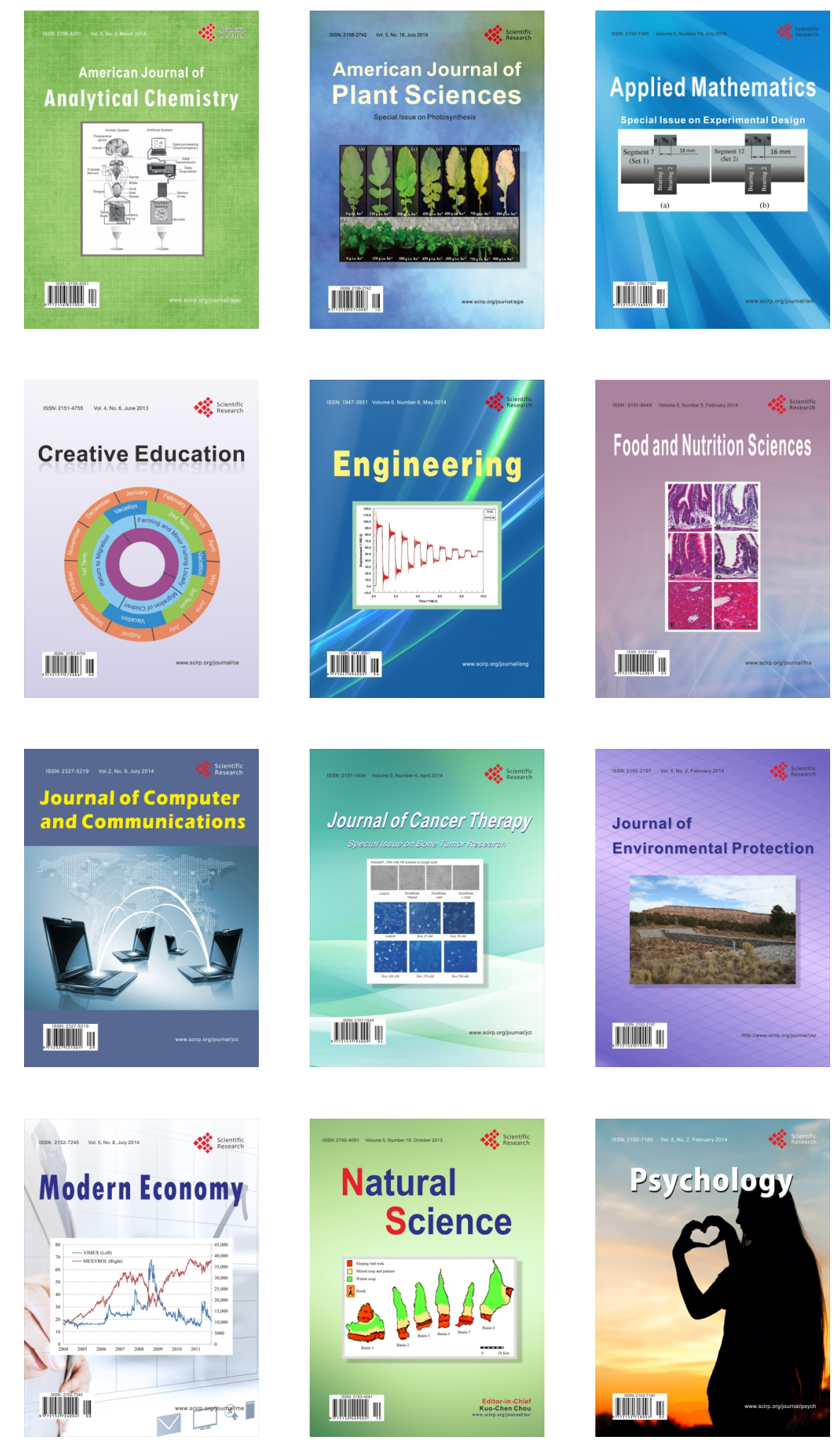